\title{
Valuing the Environmental Benefits of Canals and Canal Restoration Using House Prices
}

\author{
Stephen Gibbons ${ }^{1}$ \\ Cong Peng ${ }^{2}$ \\ Cheng Keat Tang ${ }^{3}$ \\ ${ }^{1}$ Professor of Economics Geography, Department of Geography and Environment, and Centre for Economic \\ Performance, London School of Economics, Houghton Street, England, London WC2A 2AE, STC 5.11, St \\ Clement's Building, email: s.gibbons@1se.ac.uk \\ ${ }^{2}$ Postdoctoral Researcher, Malcom Wiener Center, Harvard Kennedy School of Government, United States of \\ America, 79 JFK St, Cambridge 02138, email: cpeng@hks.harvard.edu \\ ${ }^{3}$ Assistant Professor, Department of Economics, Nanyang Technological University, Singapore, 48 Nanyang \\ Ave, HSS-04-73, 639798, Singapore email: c.k.tang@ntu.edu.sg.
}

Keywords: canals, waterways, house prices, environment, valuation, revealed preference JEL Codes: Q51; R2 


\begin{abstract}
This paper values the environmental benefits of historic, navigable canals using property values. We improve on standard methods by controlling for micro-geographic fixed effects and applying a difference-in-differences method to canal restoration. We find a localized price premium within $100 \mathrm{~m}$, around $5 \%$ before the 2008 recession, dropping subsequently to $3.4 \%$ by 2016 . These effects are driven by urban canal-side properties with a direct outlook on the canals or immediate access. These locations are also attractive for developers, with a higher proportion of new-build sales. Our estimates suggest that canals generate land value uplift of $£ 0.8-0.9$ billion in England. Appendix materials can be accessed online at: https://uwpress.wisc.edu/journals/pdfs/LE-97-4-08Gibbons-app.pdf.
\end{abstract}




\section{Introduction}

Britain has an extensive canal and navigable river network, which played a vital role in transporting goods from the Industrial Revolution through the 18th, 19th and early part of the 20th Century. The use of canals and waterways for transporting freight had all but disappeared by the mid-20th Century and many had fallen into disrepair or been abandoned. Since then, the canal and waterway network has been restored and developed into a valuable environmental and recreational amenity, providing the venue for an extensive range of tourism and leisure activities. These canals ${ }^{i}$ also provide transport corridors for walkers and cyclists along the towpaths formerly used by horses for drawing boats. It is estimated that in 2016 there were more than 4.3 million people making a total of 396 million visits to the canals for various purposes including walks, hikes, boating, fishing, and cycling (Canal and River Trust, 2016).

Our study applies standard revealed preference, "hedonic" property value methods to estimate the value of access to canals in England and Wales. There is of course a very long tradition of using the housing market to estimate the value of environmental and other non-market goods (Ridker \& Henning, 1967). Underpinning this method is the idea that in spatial equilibrium, people end up living in places where the benefits of them doing so are at least equal to the costs. Hence, the market price of houses of similar size and with similar structural characteristics but in different places, adjusts to trace out the value of those places to the population. In turn, the value of a place can be unpacked into the implicit price of its constituent components - proximity to transport, proximity to jobs, crime, quality of schooling, quality of environment, recreational facilities and so on using regression techniques. As is well known, the main empirical challenge is to separate the impact of these characteristics on house prices from the effects of unobserved confounding factors.

Although there is already a quite extensive literature on the environmental value of water 
bodies in general (Nicholls \& Crompton, 2017) much of this literature relates to rivers, streams and other natural water features. Some of this work looks at the impact of individual cases of river restoration and improvement (Streiner \& Loomis, 1995), including dam removals (Lewis \& Landry, 2017) and the planting of riparian buffers which obscured river views (Mooney \& Eisgruber, 2001). These studies suggest that river improvements, views of rivers and reduced risk of flooding are all valued by homeowners, although they shed little light on the value of the amenity value of manmade canals specifically.

The literature on canals is much more limited, consisting of a few cross-sectional analyses, often on small samples for specific cities. These suggest that properties close to canals attract a premium, $2.9 \%$ for canal-side properties and $1.9 \%$ for properties within $200 \mathrm{~m}$ in London (Garrod \& Willis, 1994), 0.074\% per metre closer to canals in Milan (Bonetti et al. , 2016) and 11\% for properties with a canal frontage in Texas (Nelson et al. , 2005). Although the literature consistently reports that households pay a premium to reside near canals and other types of waterway, the magnitude of the estimates varies across studies and contexts, calling in to question the external validity of studies carried out on specific cases (Lewis \& Landry, 2017).

Our work offers several contributions to this and the wider environmental evaluation literature. Firstly, the size of our administrative data set on the universe of transactions in England and Wales means we can restrict our estimation sample to properties with $1500 \mathrm{~m}$ of canals and estimate from variation in distance within these buffers, while still retaining more than 2 million transactions. These data cover a wide range of urban and rural contexts, improving the generalisability of the findings. Secondly, by merging price transactions data with a rich set of geographic and socioeconomic data sources we are much better able to control for, and test sensitivity to, land use, distance to geographical features, employment and demographic variables. In our preferred specifications, we further control for fixed effects at a small geographical scale - either Middle 
Layer Super Output Areas (MSOAS) or Lower Layer Super Output Areas (LSOAs) - and for differing price trends at Local Authority District level. This means we estimate the price effects from variation in the distance to canals, and associated variation in house prices, that occurs within these small geographical areas. Confounding factors that vary at a higher geographical level - such as access to labour markets - are eliminated.

Lastly, we exploit the natural experiment of the restoration of a canal in England in a difference-in-differences analysis. The difference-in-differences method is frequently applied in valuing amenities/disamenities such as proximity to transportation nodes (Gibbons \& Machin, 2005), wind farms (Gibbons et al. , 2015), exposure to air pollution (Currie et al. , 2015) (Chay \& Greenstone, 2005), crime risk (Linden \& Rockoff, 2008) and traffic (Tang, 2021). We focus on the restoration of an abandoned canal - the Droitwich Canal in the West Midlands of England which was closed in 1939. By the early 2000s the canal was overgrown, drained of water, non-navigable or completely destroyed. The canal underwent a major restoration in 2007 and was re-opened in 2011. The restoration provided an avenue for recreation activities such as boat navigation, improved the environment and provided a habitat for aquatic life. In our study, we compare price changes for properties close to the canal after the canal is restored (treatment group) with price changes for comparable properties that are unaffected by canal restoration (control group). The assumption behind this method is that prices would have evolved in the treatment group close to the Droitwich canals in much the same way as in the control group, if the Droitwich canals had not been restored. The validity of this assumption depends on the comparability between properties in the treatment and control group. Hence, we select two alternative plausible control groups: (1) properties close but slightly further away from the Droitwich canal; and (2) properties near to an existing neighbouring canal - the Worcester and Birmingham canal - that remain in continuous use and are not affected by the restoration over this period. This difference-in-differences analysis gives us 
results from a more robust causal estimation strategy, albeit on a specific case, which we can triangulate with the cross-sectional estimates for all England and Wales.

To preview our findings, analysis of the entire canal system in England and Wales suggests that proximity to canals increases house prices, although the effect is highly localised. Properties within 100 metres of a canal have a price premium of around $5 \%$ relative to those beyond $1 \mathrm{~km}$ (estimated on the whole $2002-2016$ study period). There is no impact on prices in the $100 \mathrm{~m}-1 \mathrm{~km}$ range. The local geographical extent of this effect suggests it is associated with canal-side properties and others which have immediate access or views of these waterways. The effect is bigger - around $10 \%$ - in dense urban areas. Similar effects are detected for the re-opening of the Droitwich canals. The restoration leads to a $10 \%$ increase in values for properties within $100 \mathrm{~m}$ of the restored canals.

We also investigate the association between canal proximity, and the share of new-build homes sold, as a proxy for housing construction. We observe that the proportion of new-build sales is 5.9 percentage points higher within $100 \mathrm{~m}$ of a canal compared to further away, representing a $75 \%$ relative increase.

Additional analysis reveals that there was a step change in the valuation of this amenity at the time of the recession in 2008, which persisted up to the end of our study period. The premium for living with $100 \mathrm{~m}$ of a canal halved from around $£ 520$ per year pre-recession to $£ 260$ post-recession and the proportion of new-build transactions fell accordingly. Back-of-the-envelope calculations indicate the land value uplift from the canal network was around $£ 0.8-£ 0.9$ billion in 2016 .

The remainder of the paper is as follows. Next, Section 2 describes the data and the methodology in detail. Section 3 presents and discusses the results of the analysis and Section 4 concludes. 


\section{Methods and Data}

\section{Estimation methods}

\section{Regression Specifications for National Analysis}

The underlying reasons for wanting to live near to a canal are that doing so reduces the time and cost of travelling to them and/or because it means a resident has a direct view of a canal or a canal frontage $^{\mathrm{ii}}$. We therefore use indicators of distance from a property to its nearest canal as our key variables of interest and estimate to what extent prices are lower or higher at different distances (holding other factors constant). Distances are based on full postcode, where a postcode typically contains around 17 dwellings.

We first estimate the house price premium associated with proximity to canals with a standard hedonic property price regression, estimated using ordinary least squares (OLS), that takes the following form:

$$
\ln p_{i j k t}=\alpha_{j}+\sum_{k \in K} \beta_{k} D_{i k}+\mathbf{X}_{\mathbf{i j t}}^{\prime} \theta+\tau_{j t}+\varepsilon_{i j k t}[1]
$$

where $\ln p_{i j k t}$, the dependent variable, is the natural logarithm of the price of property $i$ located in neighbourhood $j$ and sold at time $t$. To simplify notation, we use $j$ to represent various small geographical units as discussed below. The key variable of interest is $D_{i k}$. It is a set of distance band indicators at 100 metres interval and up to $1 \mathrm{~km}(K=\{1,2, \ldots, 10\})$ computed based on the Euclidean distance of property $i$ from the nearest canal. $D_{i 1}$ is a binary variable that takes the value of 1 if a property is between $0-100 \mathrm{~m}$ from a canal, and 0 otherwise. $D_{i 2}$ indicates properties that are between 100-200m from a canal and so on, up to $900-1000 \mathrm{~m}$. The key parameters of interest $\beta_{1}, \beta_{2} \ldots \ldots \beta_{10}$, capture the difference in log transacted prices for properties in given distance band relative to the baseline (properties beyond $1000 \mathrm{~m}$ from canals). We expect to observe the price 
premium decreasing with $k$ as the distance and travel cost to the canal increasing and the benefits from canals decaying. Vector $\mathbf{X}_{\mathrm{ijt}}^{\prime}$ represents fixed and time varying control variables (discussed below). Differential price trends across neighbourhoods are captured by Local Authority District $\times$ Quarter $\times$ Year trend fixed effects, $\tau_{j t}$.

There are, potentially, many unobserved confounding factors that vary with distance to a canal and affect the price directly. These include the physical characteristics of the housing, amenities like distance to employment or proximity to public transportation nodes. For example, canals in urban areas are usually found in old industrial areas, and properties near these areas are typically older and smaller. Industrial buildings in the neighbourhood could also be a dis-amenity and affecthousing values directly. Canals also generally follow natural lines along valleys that avoid gradients, so their routes may be topographically distinct from other areas in the country.

To control for these kinds of confounding factors we take the following steps. Firstly, we focus the analysis on a buffer zone close to canals, restricting the sample to properties within $1500 \mathrm{~m}$ of them. The coefficients on the distance bands in equation 1 therefore estimate the price premium relative to properties in the $1000-1500 \mathrm{~m}$ band. In this way we compare properties that are all along canal routes, but enjoy different levels of access and exposure to their environmental benefits. We further control for a rich set of fixed and time-varying housing, geographic and location characteristics denoted by $\mathbf{X}_{\mathrm{ijt}}^{\prime}$. These characteristics are recorded at either the property, postcode or Census Output Area (OA) level. For more information on the list of controls included in our analysis, refer to the Results section, table notes and Table A1 in the Appendix. Next we control for time invariant unobservables at the neighbourhood level using local geographical fixed effects either MSOA or LSOA level - as denoted by $\alpha_{j}$, so all coefficients are estimated from variation within these small geographical areas. MSOAs and LSOAs are Census geographical areas, with an average of 7,700 and 1,600 residents respectively. The identifying assumption is that, conditional on 
these control variables and fixed effects, $E\left[\varepsilon_{i j k t} \mid D_{i k}\right]=0$.

Note, the structure of equation 1 also helps us establish that the price premium estimates we obtain are causal, in that we would theoretically expect to see a distance decay profile in the estimates, with the price premium decreasing as distance and travel cost to the canal increases.

In additional analyses, we look at heterogeneity in the price premium across various observable dimensions related to the geography of the location. We also explore the way the price premium and willingness to pay for canal proximity has changed over the years in our study period. We discuss these regressions in the section where we present the results.

Demand for housing near canals could lead to increases in the supply from developers. We investigate this issue by examining whether a transaction is more likely to be a new-build sale if it is closer to a canal. To implement this analysis, we replace the dependent variable in equation 1 with an indicator of whether a sale is a new build.

\section{Difference-in-Differences Estimation}

Even with the inclusion of a large set of controls and geographic fixed effects, and the restriction to property sales around canals, the method described above might fail to control for fixed confounding factors at a very localised geographical level, below MSOA or LSOA. A more robust approach would be to estimate from changes over time in canal access and property prices at the postcode level, thus partialing out fixed confounding factors at this level (given that distance is calculated at postcode level). The limiting factor in applying this approach to the evaluation of the environmental benefits of canals is, of course, that accessibility to canals and their environmental benefits is rarely changing.

One exception is where there have been substantial canal restoration projects, bringing disused, buried and derelict canals back into use, and restoring their value as environmental and 
recreational amenities. Canal restoration projects of this type have occurred throughout Britain over many decades, often carried out by volunteers. However, only one significant project lines up with the time period of our data on housing transactions - the restoration of the Droitwich Canal in the West Midlands in the late 2000s. We therefore turn to an analysis of the impact of this restoration project on property prices in a difference-in-differences analysis in which we estimate the value of the improvements in environmental amenity the project entailed.

The Droitwich Canal is a canal formed from two canals - the Droitwich Barge Canal and the Droitwich Junction Canal - linking the River Severn and the Worcester and Birmingham canal, and passing through the centre of Droitwich, a town of 25,500 people in the county of Worcestershire. The canals were abandoned in 1939 after an Act of Parliament and fell into decline. Parts of the canals had been restored on a voluntary basis, organised by the Droitwich Canals Trust, formed for this purpose in 1973. As a result, a section of the canal in the centre of Droitwich and three locks at the eastern end had been restored by the mid-2000s. Full restoration began in 2007, a major project with a cost of $£ 11$ million funded by National Lottery grants, local councils and charitable donations. All of the canals required dredging, repair of locks and other structures. The most significant works were complete reconstruction of a section by canalising 550 metres of the River Salwarpe through Droitwich, a new tunnel under a main road to link the Barge Canal to the River Severn, improvement to a bridge on the M5 motorway, a complete new cut with four new locks, plus extensive environmental mitigations and enhancements. The project was coordinated by British Waterways, the public corporation that managed canals and waterways at that time and was scheduled to start in 2007, with planning applications were submitted in May 2007. The work was due to be completed by 2009 , although the canals were not fully restored and opened for navigation until July 2011. The history can be traced through various web sourcesiii. For an illustration for the restoration work on Droitwich Canals, refer to Figure A1 in the online Appendix. The non-technical 
summary of the project published by British Waterways (2010) describes the purpose of the project thus:

"This project will bring the canals into navigable use and will create a unique 21 mile cruising ring linking Droitwich Spa to Worcester, which can be completed in a weekend by boat. The project is not solely about navigation as it includes many works to enhance the canal corridors as a recreational and environmental resource for local people as well as visitors to the area. Canal restoration will provide a stimulus to the local economy by encouraging tourism-related businesses and will provide many benefits to the local community. It is intended that the vision will be delivered through a series of objectives including: To restore the canals to good navigable condition; To use the canals as a catalyst to stimulate sustainable regeneration in Droitwich Spa and the surrounding area; To create an environment in which a visit to the waterways is an educational and interpretative experience of the canals' history and environment; To conserve, enhance \& promote the built heritage \& environmental assets of the canal; To achieve high levels of public accessibility for all; To sustain harmony between environmental, heritage \& recreational uses.” (British Waterways 2010).

The project was evidently very ambitious in its environmental and recreational aims, and so potentially provides a useful experiment for estimating the value of these benefits to local homeowners. To implement this idea in a difference-in-differences design we need to define treatment and control groups. The control group needs to be carefully chosen such that it is likely to have followed the same counterfactual trends in outcomes as the treatment group would have done in the absence of the policy (the "parallel trends" assumption). As candidate control groups, we select properties that: (1) are between 1000 and 1500 meters from the Droitwich Canal - as in our national analysis; or (2) up to $1500 \mathrm{~m}$ from the Worcester and Birmingham Canal, a canal in the same geographical region and local economy as the Droitwich Canal, and connected to them, but which was in continuous use over the period and experienced no restoration project or consequent 
improvement in environmental quality. Figure 1 presents a map of the Droitwich Canal and Worcester and Birmingham Canal overlaid on a satellite photograph, making the general layout and similarity in the landscape crossed by each canal clear.

Another key element in our setup is the definition of the "treatment" date when the benefits from the restoration of the canals to start to materialise - which we refer to as the post-restoration date. The project extended over several years from the mid-2000s and there was some restoration activity well before that. There are two plausible choices of this post-restoration date in relation to the major restoration scheme that started in 2007. One date is the submission of planning applications around May 2007. A second is the completion and opening around September 2011. We explore the impacts using one or the other, by estimating the following regression specification:

$$
\operatorname{lnp}_{i k p t}=\sum_{k \in K} \beta_{k} D_{i k}+\sum_{k \in K} \delta_{k} D_{i k} \text { Post }_{t}+\sum_{k \in K} \eta_{k} C_{i k}+\sum_{k \in K} \gamma_{k} C_{i k} \text { Post }_{t}+\mathbf{X}^{\prime}{ }_{\mathbf{i t}} \theta+\iota_{p}+\tau_{t}+\varepsilon_{i k p t} \text { [2] }
$$

where $C_{i k}$ represents a set of distance band indicators at 100 metres interval and up to $1 \mathrm{~km}$ $(\mathrm{K}=\{1,2, \ldots, 10\})$ computed based on the Euclidean distance of property $i$ from the nearest canal, which could be Droitwich Canal or Worcester and Birmingham Canal. $D_{i k}$ is an indicator variable denoting whether property $i$ is within $k$ distance band from Droitwich Canal (e.g if $k=1$, property $i$ is within 100 meters from Droitwich Canal). Post $t$ is an indicator denoting whether property $i$ is sold after Droitwich Canal is restored. $\gamma_{1}, \gamma_{2} \ldots . \gamma_{10}$ capture the price changes with distance from the Worcester and Birmingham Canal after restoration of the Droitwich canals. The key parameters of interest, $\delta_{1}, \delta_{2} \ldots \ldots \delta_{10}$, are difference-in-difference estimates that measure the additional property price changes after canal restoration across different distance bands from Droitwich Canal. We constrain our analysis to properties not more than $1500 \mathrm{~m}$ from either Droitwich or Worcester and Birmingham Canal to mitigate the risk of unobserved neighbourhood differences from biasing our estimates. Hence, these difference-in-differences estimates compare the distance decay in the price 
changes occurring around the Droitwich canals at the time of the restoration, with the distance decay in the price changes occurring around the Worcester and Birmingham Canals (where there was no restoration). Postcode fixed effects, represented by $\left(\iota_{p}\right)$, partial out time-invariant unobserved differences at a postcode level. Other variables are similar to equation 1.

\section{Data Sources}

The main source of data for the analysis set out above is the Land Registry "price-paid" dataset that provides detailed information on transaction prices and some basic characteristics. This dataset has been linked to information from Energy Performance Certificates (EPC), which are required for all properties bought and sold in England and Wales ${ }^{\text {iv }}$. The EPC data provides a much richer description of the structure of the property. Although the EPC information only dates back to 2008, the information can be used for properties with EPCs, when they were sold in earlier periods (assuming the basic structure of the property has not changed). Given this limitation, we do not go

back beyond 2002, although the price-paid data extends back to 1995. Our full dataset covers more than 11 million property transactions from 2002 to 2017, falling to around 2 million when we restrict to $1500 \mathrm{~m}$ buffers around canals.

For each property, we observe the postcode, floor area, number of rooms, number of heated rooms, energy efficiency, house type (flat, semi-detached, terrace house) and whether the property is new build and has a fireplace. Other characteristics are available in the EPC data, but much of this is incomplete. We geographically locate each property based on its full postcode - which typically corresponds to around 17 houses. Although the coordinates are accurate to $1 \mathrm{~m}$ for the postcode centroid, there is a degree of approximation in terms of the exact location of a property due to the potential size of each postcode, particularly in sparse rural areas. Geo-referenced information of the 371 canals across England and Wales comes from the Canal \& River Trust. The 
total length of canals spans across $3,530 \mathrm{~km}^{\mathrm{v}}$.

Using geographical information system software (ArcGIS), we compute the straight-line distance between each property postcode and its nearest canal. This is the main variable of interest in this study. We further measure the proximity of each postcode from features of canals (also provided by Canal \& River Trust) that could affect home prices through channels other than the environmental and local recreational benefits. These features include bridges (benefits as crossing points), docks and wharves (industrial areas), embankments, lakes, overflow outfall and reservoirs (signifying possible flood risk). From Ordnance Survey Strategi data (Ordnance Survey, 2015), we also compute the distance between each postcode from the nearest train lines and stations, as we are concerned that properties closer to canals could be more or less accessible to these transportation modes, given that railroad and canals often follow the same transport corridors. Distance to rivers and distance to green space is taken from the OS Open Rivers and Open Greenspace datasets (Ordnance Survey, 2018a,b). Land use comes from Landcover map Landsat remote sensed data (Rowland, 2017), each postcode assigned the land use at its centroid, and categories aggregated up to 9 major groups, urban, suburban, and a rural land cover types.

Using the location of each sale, we further map each postcode to Census data units, the Middle Layer Super Output Areas (MSOA), Lower Super Output Areas (LSOA) and Output Areas (OA). There are around 180,000 OAs and 35,000 LSOAs and 7,200 MSOAs across England and Wales. OAs are the smallest geographical area in which Census data from the Office of National Statistics is collected at every decade. To control for neighbourhood differences between properties, we account for a wide array of characteristics, specifically unemployment rate, proportions owning cars, social renting, home-owning, with no education, ethnic minority residents, non-EU residents, share of lone-parent households, population and population density, all at OA level. These data are taken from the 2001 Census. The LSOA codes are also used to merge in employment dataand 
employment industry sector shares at LSOA-level. These data come from the Business Register and Employment Survey supplied via the Nomis UK data service (www.nomisweb.co.uk). The earliest comprehensive data readily available at a small area level is 2015 and we only use this year of data (matched to all years of transaction data). The data sources are set out in Table A1.

\section{Results}

\section{Descriptive Statistics}

Our main estimation sample contains 2,048,723 transactions from 159,788 postcodes, 6,979 LSOAs, 1,861 MSOAs and 160 Local Authority Districts. The means and standard deviations of the variables in our main estimation dataset of transactions are summarised in the online Appendix Table A2. Since our analysis compares house prices in places close to canals with prices in places further away, the table splits the information into three groups $0-100 \mathrm{~m}$ from a canal, between 100 and 1000 metres of a canal, and between 1000 and $1500 \mathrm{~m}$ of a canal. These summary statistics show that there are differences between properties sold close to canals and those further away on some dimensions, but not others and it is hard to observe systematic patterns.

Evidently, simply looking at mean prices is not very informative. On average, in these unadjusted figures, property prices are slightly higher in the $100 \mathrm{~m}$ zone than the $100-1000 \mathrm{~m}$ zone, but both of these zones are slightly cheaper on average than the zone beyond $1500 \mathrm{~m}$. The estimated gap between prices in the $100 \mathrm{~m}$ zone and the $100-1000 \mathrm{~m}$ depends on how it is measured, around $1 \%$ in the simple means, around 5\% when based on the average differences in log prices $(0.05)$, and around $10 \%$ when looking at price per square metre. At the same time, properties within 100m of canals are smaller, more likely to be new builds, and much more likely to be flats $(37 \%$ as compared to $16.5 \%$ elsewhere). Population density is lower, there are more social renters and more 
unqualified people in OAs within 100m of canals, but otherwise the demographic characteristics look similar across all the groups. Canals tend to follow paths of least resistance and natural lines of communication, so properties close to canals tend to be close to railways, rail stations, close to other rivers and closer to town centres. Given the canals' original purpose for transporting goods, it is not surprising to find that there is more employment on average in MSOAs close to canals, slightly more heavily represented by manufacturing, mining/utilities, accommodation/food, and business administration, and less represented by health and education services. Interestingly, residential properties within $100 \mathrm{~m}$ of canals are $52 \%$ urban and $45 \%$ suburban, whereas the rest of the sample is split $65-69 \%$ suburban, $28-32 \%$ urban. This presumably reflects that if a canal passes through a town, it typically passes through its centre, again because of their historical transportation role. Only a small proportion of properties within $1500 \mathrm{~m}$ of a canal are in places with non-urban/suburban of land cover. It is important to correct for all these structural and geographical differences when comparing prices in the various distance zones, and the results from the regression analysis we use to do this are reported in Section 3 below. The sample for the analysis of the Droitwich Canal restoration is much smaller, as it is restricted to properties within $1500 \mathrm{~m}$ of either the Droitwich or Worcester and Birmingham Canals. A selected set of descriptive statistics for this group are reported in Table A3. Here, we report means and standard deviations for the three distance groups related to the Droitwich Canal $(<100 \mathrm{~m}, 100-1000 \mathrm{~m}$ and 1000-1500m) and for the overall sample for the Worcester and Birmingham control group $(<1500 \mathrm{~m}$ from the Worcester and Birmingham canal). Again there are dissimilarities along some dimensions when we compare these groups. However, the patterns are different from those in the full England and Wales sample and even less systematic. Properties $100 \mathrm{~m}$ from the Droitwich canal are marginally smaller than those $100 \mathrm{~m}-1000 \mathrm{~m}$ away, and considerably smaller than those near the Worcester and Birmingham canal. There is a higher proportion of terraced houses close to the Droitwich Canal than elsewhere and more social renters. 
In general, statistical tests of the difference between these groups indicate that only a few of the differences are statistically significant. The simple mean price differences are not revealing of any strong patterns. The results of the difference-in-differences analysis using these data are presented below in Section 3.

\section{Regression Estimates for National Analysis}

The results from the regression analysis discussed in 2.1.1 are presented in Table 1. Column 1 of Table 1 shows the results with no control variables, other than a set of LAD-year-quarter indicator variables (to capture general variation between LADs and over time), and basic house structure variables, house type (detached, semi, terraced, flat), new/old, leasehold/freehold, floor area, number of rooms, heated rooms, fireplace, energy performance rating (a 10-point scale). Column 2 retains these control variables, but adds in controls for geographical location, specifically the distances to various features, predominant land cover, employment, and a set of MSOA fixed effects to eliminate price variation between MSOAs, as discussed in Section 2. Column 3 replaces MSOA with LSOA fixed effects (the employment variables are now excluded as these do not vary within LSOA). Column 4 includes additional controls for neighbourhood (OA) demographics.

The striking feature of the table is the $3-5 \%$ price premium for properties within $100 \mathrm{~m}$ of canals. Beyond this distance threshold, the effects in column 1 become slightly negative before becoming near zero and insignificant at around $600 \mathrm{~m}$. This pattern of negative effects between 200 and $600 \mathrm{~m}$ is evidently related to confounding factors near canals because, when we control for geographical factors in the remaining columns, these effects disappear. Likely explanations are, as discussed earlier, that canals often pass through industrial areas in towns, and these areas are likely to be less attractive to residents. The difference between the first and remaining columns illustrates the importance of carefully controlling for these kinds of geographical influences. In column 3 and 
4, when we control for LSOA fixed effects and neighbourhood demographics - including education, ethnicity, and unemployment - it is likely we are over-controlling, and that the estimated price premium is an underestimate. The estimates are also less precisely measured (wider confidence intervals). The reasons for this are firstly that LSOAs are relatively small spatial units, so within each LSOA there is relatively little variation in distance to canals, particularly in dense locations. Also the problem with controlling for demographic characteristics is that these will respond to the local housing price, because people chose where to live based on the housing costs. Poorer, less educated and ethnic minorities tend to live in lower cost places. This implies that including controls for these demographics may eliminate some of the price effects we intend to estimate. We therefore regard column 3 and 4 as robustness checks, and our preferred estimate is that in column 2 . These estimates across distance from canals are plotted in Figure 2a.

How should we interpret the key result from Table 1? These results imply that people are, on average, willing to pay $£ 7,573$ to $£ 12,579$ to reside within $100 \mathrm{~m}$ of a canal, relative to what they are prepared to pay to live elsewhere. The short distance range of this effect suggests that the value is primarily associated with canal-side properties and others with immediate access or views of the canals. There is no premium for living near a canal other than right up close to it. This lack of a price premium for moderate proximity suggests that residents are not, on average, paying to save the time it takes to walk the additional distance from home that is, say, $1500 \mathrm{~m}$ rather than $500 \mathrm{~m}$ away. If canal users are doing so only occasionally, or if their primary motivation is to exercise, this finding is not too surprising. It is worth noting that people likely differ in the value they place on canal-side properties and immediate access to canals. Because properties with this access are scarce, the values estimated here cannot safely be generalised to the whole population, because residents with the highest willingness to pay are those who end up owning the homes, and it is their willingness to pay which determines the market price. See Bayer et al. (2007) for discussion of 
these issues. The values should thus be seen as upper bounds to the value of canal-side locations to the average person in the population.

These results do not identify any specific feature of canals that might be attractive. In additional analysis we looked at the effects of specific features - locks, aqueducts, wharves, and canalised rivers - alongside the basic effects of canal proximity. We found no interesting patterns related to aqueducts or wharves, but there is a significant (at $10 \%$ level) price premium associated with canal locks, and an insignificant effect of canalised rivers within 100m, of a similar magnitude to that for canals ${ }^{\mathrm{vi}}$. This pattern for locks is illustrated in the online Appendix Figure A2. There is an additional effect from locks, of around $4.5 \%$ within $100 \mathrm{~m}$ falling to $3 \%$ at $200 \mathrm{~m}$, although the estimates are only statistically significant at the $10 \%$ level. Some of this effect may be driven by the desirability of former lock keeper's canal-side cottages, but there may be some heritage value associated with locks in general.

In the next analysis in this section, we look at how the price effects from canal proximity vary by type of location. Here we focus only on the effects of being within 0-100 metres, given the lack of any effects elsewhere. Table 2, column 1 shows the differences by built-up urban and non-urban locations (using the land cover categories described in Section 2). The first row of column 1 indicates that outside urban areas, the price premium for the $0-100 \mathrm{~m}$ band is $2.7 \%$. This increases by an additional $7 \%$ in urban areas, making the total effect in urban areas around $10 \%$. A plausible explanation for this finding is that canals offer particular environmental and recreational benefits in urban areas, where there is limited green space available, and canal-side locations may be particularly coveted. Urban in this land cover data refers to the densest parts of cities.

Column 2 repeats the analysis for suburban and urban areas, which represent over $95 \%$ of the sample. Here we can see that all of the basic premium for canal proximity is driven by urban and suburban locations, and the effect in rural places (given by the first row of column 2) is 
insignificantly negative. The implied premium for living within $100 \mathrm{~m}$ in urban and suburban areas in these estimates is $5.9 \%$ (this is slightly higher than in Table 1, because here we are comparing 0 $100 \mathrm{~m}$, with 100-1500m). We also double checked for effects at higher distance bands in the urban/suburban sample but found none. Column 3-4 look at differences by whether a property is close to other rivers or green space which might provide alternative recreational and environmental services, but we find no evidence that this matters in general in the national sample, even if it matters to urban populations as evidenced by column 1 .

It is useful to translate the percentage premium on house prices into monetary equivalents, which represent willingness to pay for canal-side amenities - i.e. how much households are willing to give up on other expenditure in order to enjoy homes close to canals. Some care is needed in doing this, as we have estimated an average percentage premium over the whole period, but average house prices have doubled over the period from 2002 to 2017 so it is not necessarily appropriate to apply the percentage uplift to current prices to get the monetary equivalent. Instead, we first estimate the percentage price premium for properties within $0-100 \mathrm{~m}$ in each year. Figure $2 \mathrm{~b}$ plots these results. We do not report 2017 as our data only spans part of this year. The figures for each year after 2002 need to be added to the figure of 0.081 in 2002 to get the relevant percentage increase in that year. From the graph it is clear that the percentage premium remained stable from 2002 up until 2007. From then on it fell considerably, the obvious explanation being a shift in the housing market following the great recession in 2008. It is well known that the character of the housing market has changed since then, with much lower transaction volumes.

In Table 3 we report the monetary equivalents for each year, obtained by multiplying the percentage canal premium for each year by the mean price in the sample of properties $0-1500 \mathrm{~m}$ from a canal in each year (the table shows the amounts in nominal and real 2016 values, plus the annual equivalents assuming a discount rate of 3.5\%). Evidently, willingness to pay has declined 
substantially post-recession. Prior to 2008 , households were willing to pay around $£ 520$ per year to live within 100 metres of a canal (the mean in the 2002-2007 period). From 2008 onwards, this figure has fallen to half that at $£ 260$. The average overall is $£ 370$ in 2016 prices.

Next, we look at the transactions of new build homes, as explained at the end of Section 2. The aim here is to investigate whether demand for canal locations shows up in the quantity of new housing constructed, as well as in prices. The results for the whole study period on the national sample are reported in Figure 3a, which reports the coefficients and confidence intervals in the regression of the new-build dummy variable on the distance-to-canal dummies. Control variables are otherwise similar to 1, column 3, with MSOA fixed effects. Evidently, the probability of a transaction being a new build is significantly higher closer to canals over this period, by around $5.9 \%$. What does this mean in terms of the number of new homes attributable to the canal? There are around 63,700 unique homes in the $100 \mathrm{~m}$ buffer sold between 2002 and 2017, and 10,500 of these are newly built over this period. The rate of new building in the area outside the $100 \mathrm{~m}$ zone is $7.8 \%$, so the additional $5.9 \%$ means the rate of new building in the $100 \mathrm{~m}$ zone is $76 \%$ higher. This means that we would expect $0.078 \times 63,700=4967$ new homes in the $100 \mathrm{~m}$ zone if the new-build rate was the same as elsewhere. Our estimates attribute an additional $0.059 \times 63,700=3758$ homes to the existence of demand for a canal-side location (rather than other features of the land near the canal; the remaining $10,500-3758=6742$ is presumably due to these other factors). Although it is impossible to rule out that this effect is still partly due to the kind of land and existing buildings available, i.e. is driven by the supply side of the market, the combination of more new builds and positive price effects from the previous analysis suggests, fairly unambiguously, that these effects are demand driven.

This average figure of $5.9 \%$ in fact masks a much more nuanced picture of changes in the transactions of new build properties close to canals over the period. Figure $3 \mathrm{~b}$ repeats the analysis with 
interactions with year indicators, analogous to Figure $2 \mathrm{~b}$. The pattern is startling: the probability of a transaction being a new build was around $8 \%$ higher closer to canals at the beginning of the period, but started to fall rapidly around the time of the 2008 recession, with new build transactions becoming less prevalent close to canals than further away by 2011. Coupled with the evidence on the fall in the price premium over this period, these results suggest a drop in new build transactions as demand and willingness to pay for canal-side locations fell. Other work has shown a fall in willingness to pay for environmental amenities during the recession (Cho et al. , 2011), but we are not aware of other work that has found that these effects might be long lasting.

One concern, given these results on the sales of new build properties close to canals is the possibility that part of the price premium we observed for canal-side locations could be due to new builds, if new builds are more prevalent in canal side locations and if new builds command higher prices. Although our main price regressions controlled for whether or not a transaction is a new build, we investigated this question in more detail by re-estimating the property price regressions: on second hand homes only; with interactions between new-build and canal-proximity dummies; with interactions between new-build and canal-proximity dummies, alongside interactions between urban and canal-proximity dummies, and alongside urban $\times$ new-build $\times$ canal-proximity dummies. The results are shown in Table A4 in the online Appendix. Although we find that there are indeed high premia for new properties in canal-side locations, and even higher premia for new build properties in urban areas in canal-side locations, these are not the primary drivers of the price premium we observe in our main estimates.

\section{Difference-in-Differences Estimates}

In this section, we report the results of the difference-in-differences analysis of the Droitwich Canal restoration described in Section 2. As discussed in that section, these results relate to the impact that 
the restoration had on the relationship between canal distance and price in the Droitwich area, compared to a control area near the Worcester and Birmingham Canal. The presentation of the results is otherwise similar to the main results in Section 3 above.

Figure 4 summarises our key estimates $\left(\delta_{k}\right)$ graphically, with point estimates and $90 \%$ confidence intervals. Figure 4a shows the impact of the restoration using a post-intervention date of May 2007, the date the main restoration period began, Figure $4 \mathrm{~b}$ shows the additional effects - on top of those related to the start of the renovation - occurring around the official opening date in 2011. The impact shown in Figure 4a is thus a short run effect from 2007 to 2011. Figure 4c simply reports the effect of the start of renovation in May 2007, without controlling for opening, to give a clearer picture of the overall change before and after this time. Note, the regressions used to derive these estimates control for full postcode fixed effects - i.e. eliminate all fixed-over-time differences in prices and characteristics between postcodes - hence do not include the controls for distance to transport and other features or employment, since these do not vary within postcode. We include interactions between neighbourhood (OA) 2001 census demographics and the post-intervention indicator to control for possible spurious price trends related to these characteristics.

The plots in Figure $4 \mathrm{a}$ and $4 \mathrm{c}$ bear a similarity to those from the national estimates in Table 1, although the methods used to estimate them are substantially different. Here we are estimating only from the changes in prices over time near the Droitwich Canal around the time of the start of the major restoration, compared to the changes over time occurring over the same time in the control group. The effect of the restoration within $0-100 \mathrm{~m}$ is large before opening, at around $11.9 \%$, although there is a marked decline after opening. Taken together the overall impact reported in Figure $4 \mathrm{c}$ is around $7.6 \%$, which is slightly larger than the $5 \%$ found on the national cross-sectional analysis in Table 1, although given the wider confidence intervals the figures are statistically similar. These patterns of distance decay in these estimates are not so clear cut, with some evidence of price 
uplift in 400-1000m bands. It is possible that the effects are spuriously related to confounding factors specific to the Droitwich area compared to the control Worcester area. Nevertheless, the sharp distance decay between $0-100 \mathrm{~m}$ and the rest provides some assurance that the $0-100 \mathrm{~m}$ effect can be treated as a "causal" impact of the canal restoration on immediately proximate property prices.

The estimates from this difference-in-differences evaluation are less precise than those from the cross-sectional analysis, and are based on a single case study area and much smaller sample. There are risks in looking at a single case like this, in that the estimates may be influenced by local price trends specific to the area. The number of affected properties is small - around 289 sales occur in 36 postcodes within 100m band between 2002 and 2017. It is, however, reassuring that this methodology arrives at results which point in the same direction as the national cross-sectional analysis. The likely interpretation is that households value the environmental amenities associated with living very near to a canal, or alongside the canal, and the Droitwich Canal restoration increased the quality of these amenities as the project intended. A back-of-the-envelope calculation, multiplying the number of unique properties transacted since 2007 within $100 \mathrm{~m}$ of the Droitwich Canal (176), by the mean price in 2007 in the $0-1500 \mathrm{~m}$ sample area $(£ 195,000)$ and the percentage increase implied by Figure 4 (7.6\%), suggests that the total gain in value for these homes was $£ 2.6$ million. This figure of course ignores the homes that have not yet sold, the value uplift to land that has yet to be developed, and the value ignores any benefits not captured in the housing market.

\section{Conclusions}

Canals potentially provide a desirable recreational and environmental amenity. In this paper, we estimate the monetary-equivalent value of this amenity to local residents using house prices. The revealed preference framework adopted in this study is a standard approach to valuing non-market 
goods in the environmental and urban economics literature. Analysis of the effects of canal proximity for the whole of the England and Wales network indicates that households are willing to pay a $5 \%$ premium to live within $100 \mathrm{~m}$ of a canal, on average over the $2002-2017$ period. The price premium falls substantially after the great recession from about $8.1 \%$ down to $3.4 \%$ in 2016 , corresponding to annual monetary willingness to pay of around $£ 520$ pre-recession, and $£ 260$ postrecession, in 2016 prices. We find no price premium for living close to a canal but beyond 100m, which suggests that the effect is driven predominantly by canal-side properties, and others with a direct outlook on the canals or immediate access. We further observe a higher proportion of newbuild sales within $100 \mathrm{~m}$ of canals relative to elsewhere over the period - a $5.9 \%$ increase on a $7.8 \%$ baseline, so around $75 \%$ higher - suggesting considerable response in construction to this demand for canal-side homes. However, the rate of new build sales fell dramatically post-recession, in tandem with the fall in the price premium. A unique application of a difference-in-differences evaluation methodology to the restoration and environmental rehabilitation of the Droitwich Canal in the West Midlands supports the key findings on prices.

As an interesting, if very imprecise exercise, we calculate the potential implied land and property value uplift from the canal network. The length of the network covered in this analysis is $3500 \mathrm{~km}$. The price effects extend over $100 \mathrm{~m}$ either side of the canal, so the affected area is $0.2 \times$ $3500 \mathrm{~km}=700 \mathrm{~km}^{2}$, which is just under half the area of Greater London. Though we do not have the exact figure in our data, around $10 \%$ of the land of England is urban/suburban and so developed or hypothetically developable, so the price uplift from canals would affect about $70 \mathrm{~km}^{2}$, or 70 million $m^{2}$ of residential or potential residential land. Price per square metre of residential floor space in our sample of postcodes with $1.5 \mathrm{~km}$ of the canals in 2016 is around $£ 2700$. If residential land prices are around two-thirds of this, they would be around $£ 1800$ per square metre on average. The $3.4 \%$ premium for living close to canals in 2016 , thus implies a land value uplift of $0.045 \times 1800 \times 70$ 
million $=£ 4.3$ billion pounds.

Of course, not all of this urban land is built on for housing or ever likely to be. The proportion built on is more like $2.2 \%$, so the implied increase in value of developed land is closer to $£ 0.9$

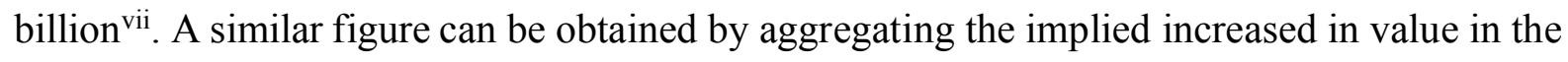
housing stock in our data. There are around 100,000 unique properties within $100 \mathrm{~m}$ of a canal that transacted at least once over the entire 1995-2017 period on which we have data. The average price outside this distance band is $£ 235,000$ in 2016 . The $3.4 \%$ uplift to property prices therefore implies a total increase in value of around $£ 0.8$ billion $(0.034 \times 235,000 \times 100,000)$ aggregating across all the affected homes ${ }^{\text {viii }}$.

Acknowledgements: This project was funded by ESRC grant ES/M010341/1 and The Canal and Rivers Trust 


\section{References}

Bayer, Patrick, Ferreira, Fernando, \& McMillan, Robert. 2007. “A Unified Framework for Measuring Preferences for Schools and Neighborhoods." Journal of Political Economy, 115(4): 588-638.

Bonetti, Federico, Corsi, Stefano, Orsi, Luigi, \& De Noni, Ivan. 2016. “Canals vs. streams: To what extent do water quality and proximity affect real estate values? A hedonic approach analysis." Water, 8(12): 577.

British Waterways. 2010. Restoration of the Droitwich Canals. archived Wayback Machine, https://web.archive.org/web/20100924192725/http://britishwaterways.co.uk/media/ documents/DroitRestorationNonTechnicalSummary.pdf.

Canal and River Trust. 2016. Canal and River Trust Annual Report 2016-2017. Retrieved from url:https://canalrivertrust.org.uk/media/original/33176-annual-report-2016-17.pdf.

Chay, Kenneth Y, \& Greenstone, Michael. 2005. "Does air quality matter? Evidence from the housing market." Journal of Political Economy, 113(2): 376-424.

Cho, Seong-Hoon, Kim, Seung Gyu, \& K.Roberts, Roland. 2011. "Values of environmental landscape amenities during the 2000-2006 real estate boom and subsequent 2008 recession." Journal of Environmental Planning and Management, 54(1): 71-91.

Currie, Janet, Davis, Lucas, Greenstone, Michael, \& Walker, Reed. 2015. "Environmental health risks and housing values: evidence from 1,600 toxic plant openings and closings." American Economic Review, 105(2): 678-709.

Garrod, Guy, \& Willis, Ken. 1994. “An economic estimate of the effect of a waterside location on property values." Environmental and Resource Economics, 4(2): 209-217.

Gibbons, Stephen, \& Machin, Stephen. 2005. "Valuing rail access using transport innovations." Journal of Urban Economics, 57(1): 148-169.

Gibbons, Steve, Overman, Henry G., \& Patacchini, Eleonora. 2015. “Chapter 3 - Spatial Methods." Pages 115-168 of: Gilles Duranton, J. Vernon Henderson, \& Strange, William C. (eds), Handbook of Regional and Urban Economics. vol. 5. Elsevier.

Lewis, Lynne Y, \& Landry, Craig E. 2017. "River restoration and hedonic property value analyses: Guidance for effective benefit transfer." Water resources and economics, 17: 20-31.

Linden, Leigh, \& Rockoff, Jonah E. 2008. "Estimates of the impact of crime risk on property values from Megan's laws.” American Economic Review, 98(3): 1103-27. 
Mooney, Sian, \& Eisgruber, Ludwig M. 2001. "The influence of riparian protection measures on residential property values: the case of the Oregon plan for salmon and watersheds." The Journal of Real Estate Finance and Economics, 22(2-3): 273-286.

Nelson, Glyn, Hansz, J Andrew, \& Cypher, Matthew L. 2005. "The Influence of Artificial Water Canals on Residential Sale Prices." Appraisal Journal, 73(2).

Nicholls, S, \& Crompton, JL. 2017. "The effect of rivers, streams, and canals on property values." River research and applications, 33(9): 1377-1386.

Ordnance Survey. 2015. Strategi. Downloaded from EDINA Digimap Ordnance Survey Service http://digimap.edina.ac.uk.

Ordnance Survey. 2018a. OS Open Greenspace. Downloaded from EDINA Digimap Ordnance Survey Service http://digimap.edina.ac.uk.

Ordnance Survey. 2018b. OS Open Rivers. Downloaded from EDINA Digimap Ordnance Survey Service http://digimap.edina.ac.uk.

Ridker, Ronald G., \& Henning, John A. 1967. "The Determinants of Residential Property Values with Special Reference to Air Pollution." The Review of Economics and Statistics, 49(2): $246-257$.

Rowland, C.S., Morton, R.D., Carrasco L., McShane G., O’Neil A.W. \& Wood C.M. 2017. Land Cover Map 2015 (vector, GB).

Streiner, Carol F, \& Loomis, John B. 1995. "Estimating the benefits of urban stream restoration using the hedonic price method." Rivers, 5(4): 267-278.

Tang, Cheng Keat. 2021. "The cost of traffic: evidence from the London congestion charge." Journal of Urban Economics, 121(1): 103302. 


\section{Figures and Tables}
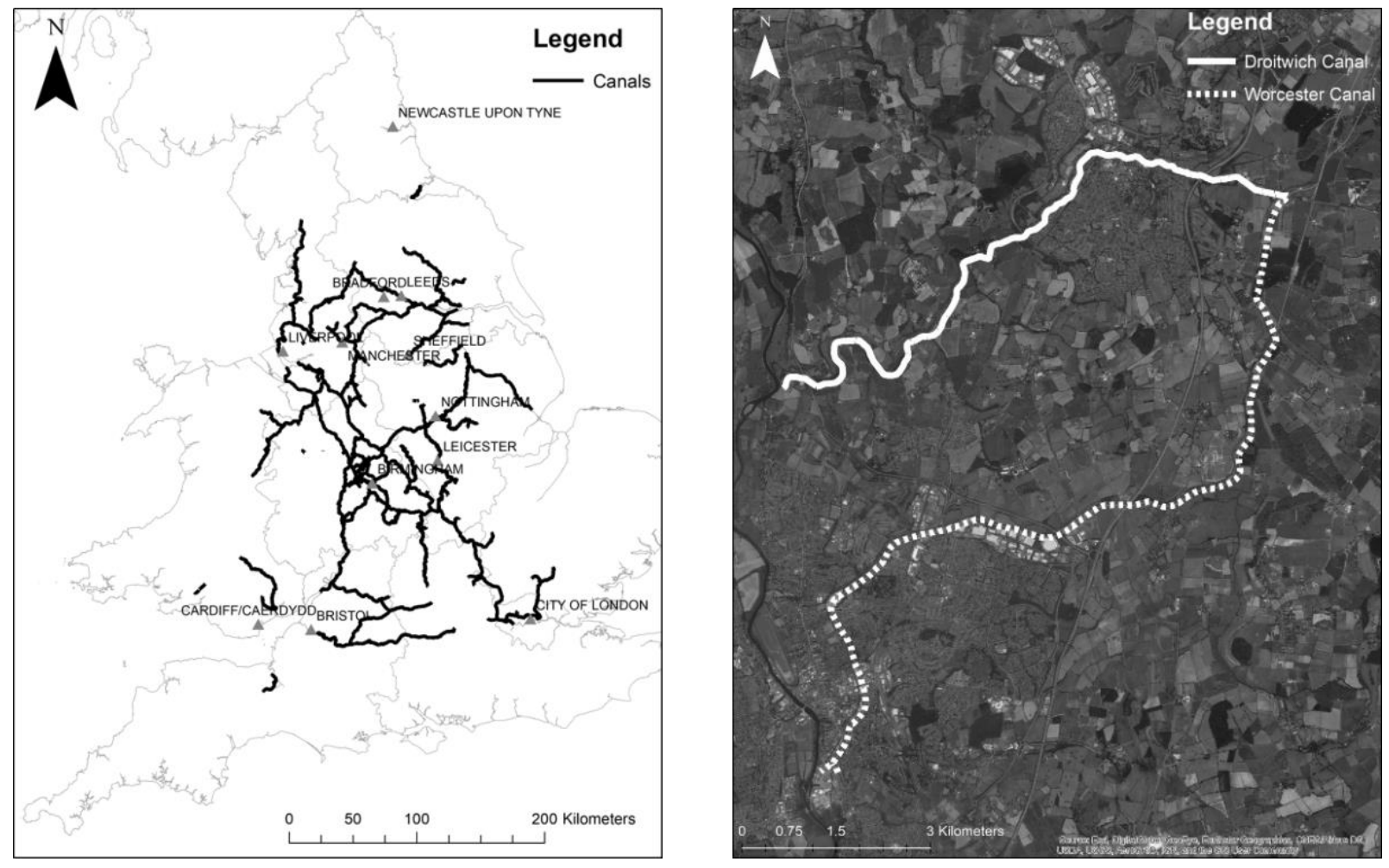

Figure 1: Map of waterways managed by the Canal and River Trust $\&$ zoomed in map of Droitwich Canal and Worcester Canal 


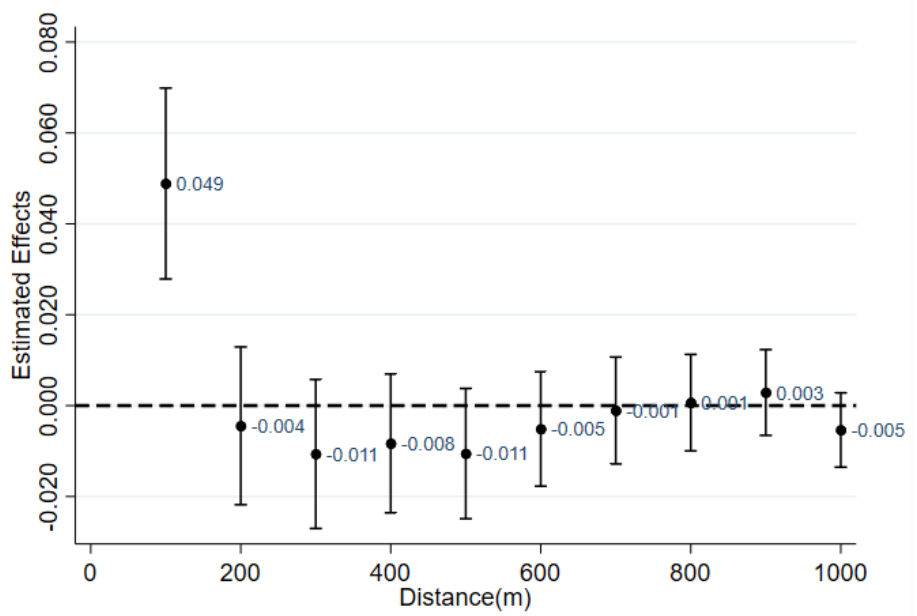

(a)

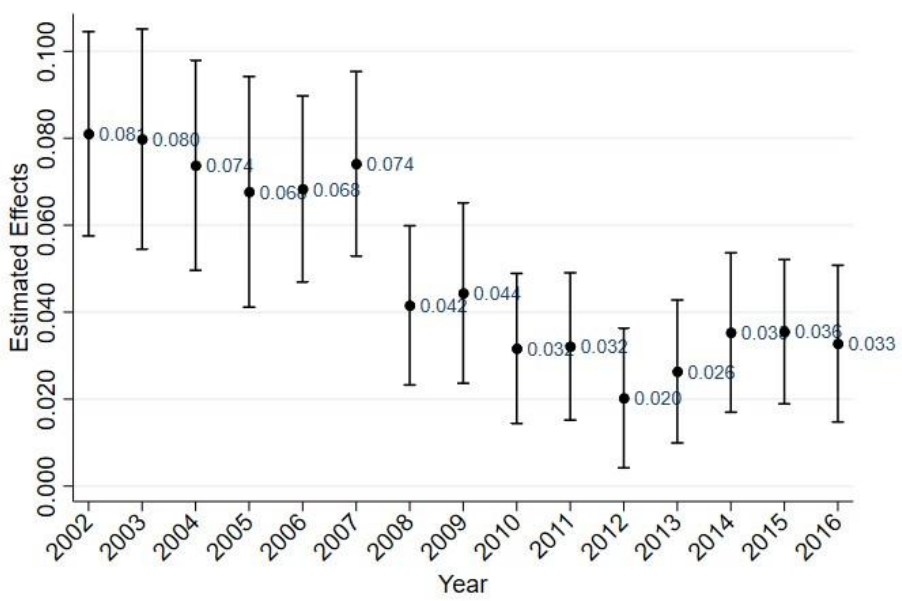

(b)

\section{Figure 2: Estimated effects of canal proximity on house prices}

Note: Figure (a) plots the estimated effects of canal proximity on house prices at $100 \mathrm{~m}$ distance bandwidths. Corresponding regression estimates are reported in column 2 of Table 1 . The set of control variables includes house structure, location, land cover, employment characteristics, LADs $\times$ Years $\times$ Quarters fixed effects and MSOA fixed effects. Refer to Table A1 in Data Appendix for detailed description of the control variables. Average transacted price for regression sample is $£ 234,908$. Standard errors are clustered at MSOA level. Tails denote $95 \%$ confidence intervals. Figure (b) plots the estimated effects on house prices for properties within 0 to $100 \mathrm{~m}$ from the nearest canal across the years, from 2002 to 2016. The set of control variables includes house structure, location, land cover, employment characteristics, LADs $\times$ Years $\times$ Quarters fixed effects and MOSA fixed effects. Standard errors are clustered at MSOA level. Tails denote $95 \%$ confidence intervals. 


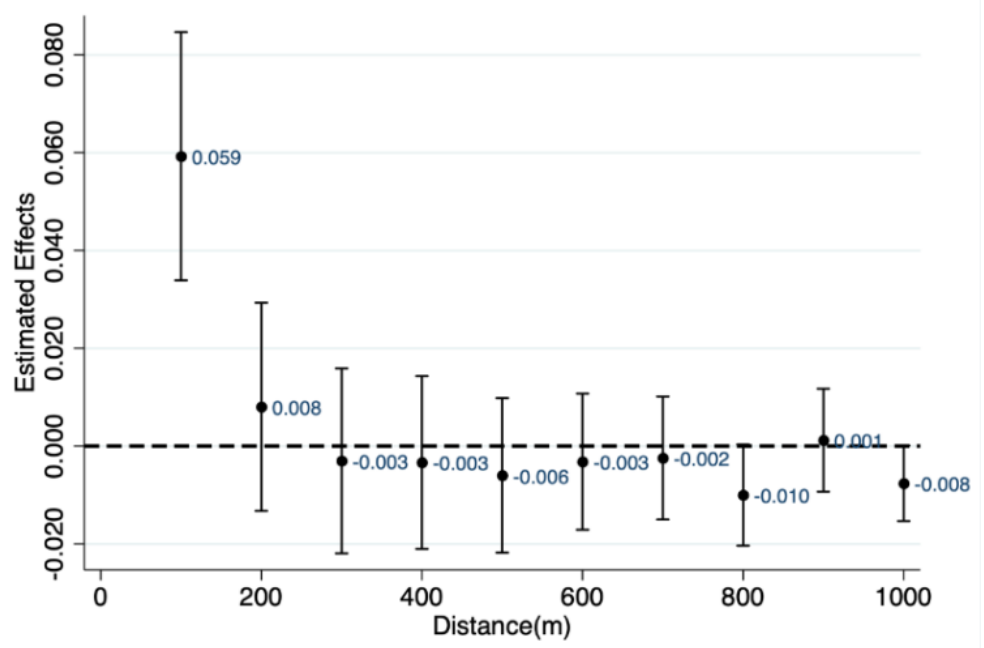

(a)

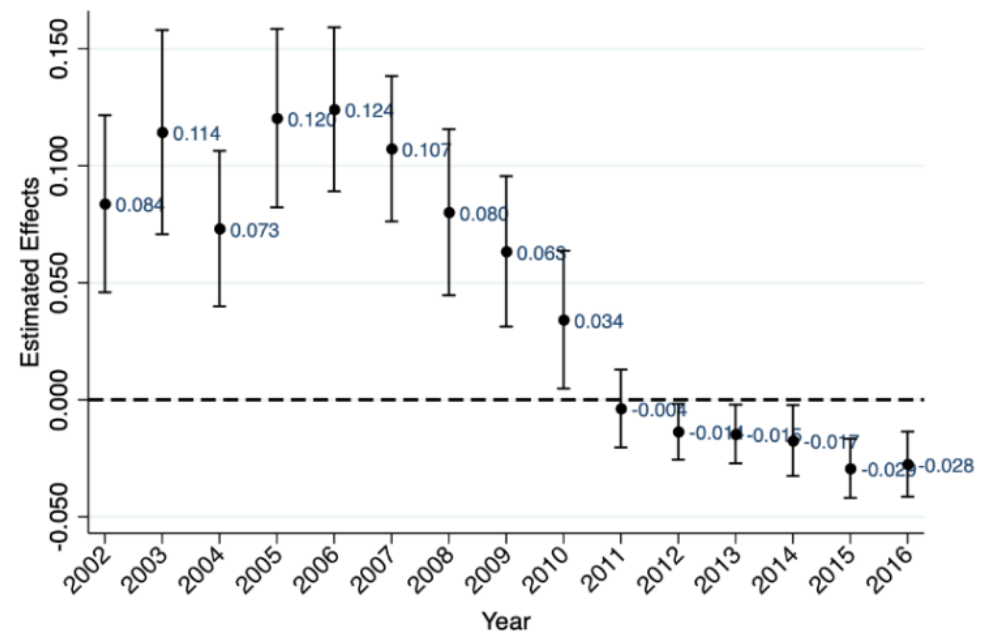

(b)

Figure 3: Estimated effects of canal proximity on (a) probability of new build sales \& (b) on probability of new build sales by year

Note: This figure plots the estimated effects of canal proximity on the probability of new build sales. Figure (a) plots the estimated effects over distance while Figure (b) plots the estimated effects of canal proximity on the probability of new build sales for properties within 0 to $100 \mathrm{~m}$ from the nearest canal across the years, from 2002 to 2016 . Dependent variable is a binary variable denoting whether transaction is new sale. The set of control variables includes location, land cover, employment characteristics, LADs $\times$ Years $\times$ Quarters fixed effects and MOSA fixed effects. Standard errors are clustered at MSOA level. Tails denote $95 \%$ confidence intervals. 


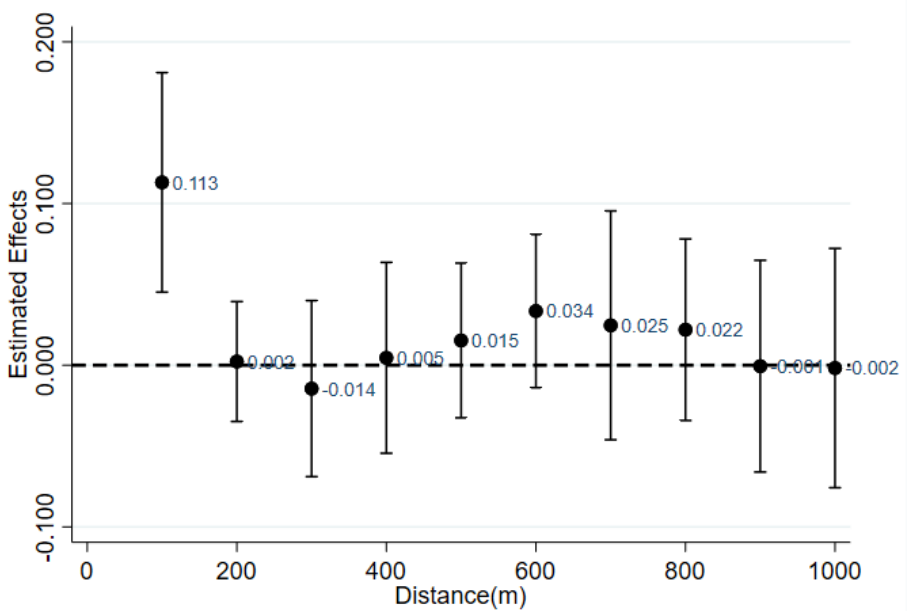

(a)
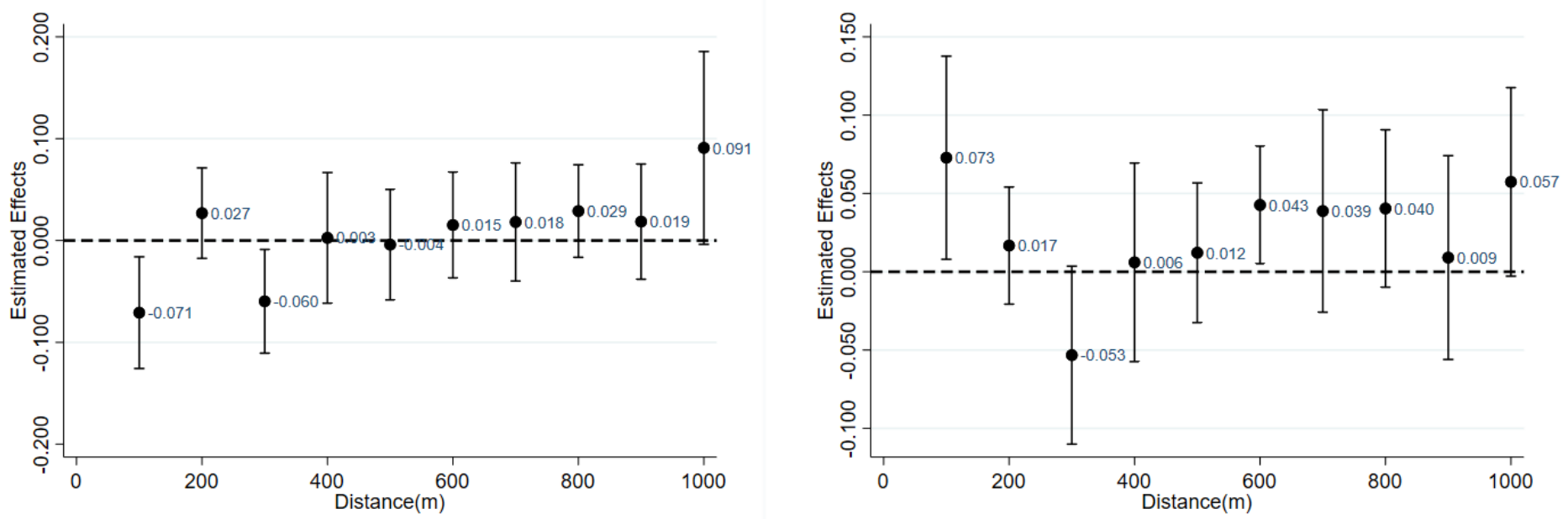

(b)

(c)

Figure 4: Price effects from Droitwich Canal restoration at different distances

Note: These figures plot the estimated effects for proximity to the Droitwich Canal on house prices. Corresponding regression estimates are reported in column $1 \& 2$ (b) of Table A4. Figure (a) plots the effects from the restoration date in 2007 till 2011 before the Droitwich Canal is reopened. Figure (b) plots the additional effects after the Droitwich Canal is reopened after 2011 (i.e. in addition to the effects in (a)). Figure (c) plots the effects from the restoration date in 2007 till 2011 before the Droitwich Canal is reopened without controlling separately for re-opening effects. The set of control variables includes house structure controls, neighbourhood controls interacted with post intervention indicators and postcode fixed effects. Standard errors are clustered at postcode level. Tails denote $90 \%$ confidence intervals. 
Table 1: Baseline results. Effects of canal proximity on house prices

\begin{tabular}{|c|c|c|c|c|}
\hline Distance Bands & $(1)$ & $(2)$ & (3) & (4) \\
\hline \multirow[t]{2}{*}{$<=100$ meters } & $0.0522 * * *$ & $0.0489 * * *$ & $0.0400 * * *$ & $0.0317 * * *$ \\
\hline & $(0.0107)$ & $(0.0107)$ & $(0.0100)$ & $(0.0091)$ \\
\hline \multirow[t]{2}{*}{101 to 200 meters } & -0.0052 & -0.0045 & 0.0009 & -0.0003 \\
\hline & $(0.0079)$ & $(0.0088)$ & $(0.0086)$ & $(0.0079)$ \\
\hline \multirow[t]{2}{*}{201 to 300 meters } & $-0.0201 * * *$ & -0.0106 & -0.0038 & -0.0025 \\
\hline & $(0.0070)$ & $(0.0084)$ & $(0.0078)$ & $(0.0072)$ \\
\hline \multirow[t]{2}{*}{301 to 400 meters } & $-0.0182 * * *$ & -0.0083 & -0.0043 & -0.0013 \\
\hline & $(0.0067)$ & $(0.0078)$ & $(0.0072)$ & $(0.0065)$ \\
\hline \multirow[t]{2}{*}{401 to 500 meters } & $-0.0247 * * *$ & -0.0106 & -0.0060 & -0.0009 \\
\hline & $(0.0068)$ & $(0.0073)$ & $(0.0067)$ & $(0.0061)$ \\
\hline \multirow[t]{2}{*}{501 to 600 meters } & $-0.0124^{*}$ & -0.0051 & -0.0005 & 0.0031 \\
\hline & $(0.0064)$ & $(0.0064)$ & $(0.0061)$ & $(0.0055)$ \\
\hline \multirow[t]{2}{*}{601 to 700 meters } & -0.0069 & -0.0011 & -0.0005 & 0.0028 \\
\hline & $(0.0063)$ & $(0.0060)$ & $(0.0057)$ & $(0.0050)$ \\
\hline \multirow[t]{2}{*}{701 to 800 meters } & $-0.0104 *$ & 0.0006 & 0.0007 & 0.0039 \\
\hline & $(0.0062)$ & $(0.0054)$ & $(0.0047)$ & $(0.0042)$ \\
\hline \multirow[t]{2}{*}{801 to 900 meters } & -0.0036 & 0.0029 & 0.0037 & 0.0035 \\
\hline & $(0.0059)$ & $(0.0048)$ & $(0.0040)$ & $(0.0037)$ \\
\hline \multirow[t]{2}{*}{901 to 1000 meters } & $-0.0144 * *$ & -0.0054 & 0.0003 & 0.0003 \\
\hline & $(0.0057)$ & $(0.0042)$ & $(0.0036)$ & $(0.0034)$ \\
\hline LADs $\times$ Years $\times$ Quarters & $\mathrm{X}$ & $\mathrm{X}$ & $\mathrm{X}$ & $\mathrm{X}$ \\
\hline House Structure $\mathrm{X}$ & & $\mathrm{X}$ & $X$ & $\mathrm{X}$ \\
\hline Location & & $\mathrm{X}$ & $\mathrm{X}$ & $\mathrm{X}$ \\
\hline Land Cover & & $\mathrm{X}$ & $\mathrm{X}$ & $\mathrm{X}$ \\
\hline Employment & & $\mathrm{X}$ & $\mathrm{X}$ & $\mathrm{X}$ \\
\hline MSOA Fixed Effects & & $\mathrm{X}$ & & \\
\hline LSOA Fixed Effects & & & $\mathrm{X}$ & \\
\hline Neighbourhood & & & & $\mathrm{X}$ \\
\hline Observations & 2048723 & 2048723 & 2048723 & 2048723 \\
\hline R-squared & 0.72 & 0.78 & 0.80 & 0.81 \\
\hline Mean House Prices & 234907.76 & 234907.76 & 234907.76 & 234907.76 \\
\hline
\end{tabular}

Note: Dependent variable is natural logarithm of transacted house prices. Housing structure characteristics include size, number of rooms, fireplace, new build, energy efficiency, flat type and tenure. Location controls include distance from various nature features (river, lakes, docks, bridges, embankments, reservoirs), transportation nodes (rail, rapid lines) and town centre. Land cover controls include dummy variables for land uses around the postcode that include urban land, suburban, arable land, grassland, rock land, woodland. Employment controls include share of employment in various sectors (e.g manufacturing, wholesale, retail) collected at the LSOA of postcode. Neighbourhood controls include unemployment rate, population density, population size, percentage of residents who are illiterate, non-European, non-white, and percentage of households with lone parents, without cars, who are social renters, who are homeowners. All these neighbourhood controls are collected at OA level. See Table A1 in Data Appendix for more details on the variables included. Absolute price change is computed by multiplying the average transacted prices with the estimated premium for properties within 100 meters from the nearest canal. Standard errors are clustered at LSOA level in columns 1,3 and 4 and clustered at MSOA level in column $2 .{ }^{*}, * *, * * *$ denotes significance level at $10 \%, 5 \%$ and $1 \%$ respectively. 
Table 2: Heterogeneous effects of canal proximity on house prices

\begin{tabular}{lllll}
\hline Distance Bands & $(1)$ & $(2)$ & $(3)$ & $(4)$ \\
& Urban & Urban/Suburban & No rivers & No green space \\
\hline$<=100$ meters & $0.0268^{* * *}$ & 0.0136 & $0.0583^{* * *}$ & $0.0567^{* * *}$ \\
& $(0.0058)$ & $(0.0164)$ & $(0.0086)$ & $(0.0090)$ \\
$<=100$ meters in area specified & $0.0710^{* * *}$ & $0.0726^{* * *}$ & -0.0151 & -0.0015 \\
& $(0.0168)$ & $(0.0181)$ & $(0.0174)$ & $(0.0128)$ \\
\hline Observations & 2048723 & 2048723 & 2048723 & 2048723 \\
R-squared & 0.78 & 0.78 & 0.78 & 0.78 \\
Absolute price change (mean) $£$ & 24122.28 & 14274.93 & 10384.62 & 13324.18 \\
\hline
\end{tabular}

Note: Dependent variable is natural logarithm of transacted house prices. Column headings: (1) Urban area; (2) Urban or suburban area; (3) No rivers within 870 metres (top quartile); (4) No green space within 250 metres (top quartile). Specification controls for structural characteristics, distances to other water features, rail and town centres, land cover categories, employment variables at LSOA level, MSOA fixed effects, LAD $\times$ year $\times$ quarter fixed effects. See Table A1 for the exact list of variables included for each set of controls. Absolute price change is calculated by multiplying the average transacted prices on the estimated premium (main effect plus interaction effect) for properties within 100 meters from canal. Average transacted price for regression sample is $£ 234,908$. Standard errors are clustered at LSOA level. $*, * *, * * *$ denotes significance level at $10 \%, 5 \%$ and $1 \%$ respectively.

Table 3: Willingness to pay for property $0-100 \mathrm{~m}$ from canals, by year

\begin{tabular}{|c|c|c|c|c|}
\hline & (1) & & (2) & (3) \\
\hline Year & $\begin{array}{l}\text { Willingness } \\
\text { £nominal }\end{array}$ & to pay & Willingness to pay $£ 2016$ & $\begin{array}{l}\text { Annual equivalent at } 3.5 \% \\
\text { discount rate }\end{array}$ \\
\hline 2002 & 9660 & & 13058 & 457 \\
\hline 2003 & 10886 & & 14520 & 508 \\
\hline 2004 & 11622 & & 15298 & 535 \\
\hline 2005 & 11278 & & 14542 & 509 \\
\hline 2006 & 12180 & & 15350 & 537 \\
\hline 2007 & 14211 & & 17494 & 612 \\
\hline 2008 & 7755 & & 9220 & 323 \\
\hline 2009 & 8226 & & 9566 & 335 \\
\hline 2010 & 6447 & & 7262 & 254 \\
\hline 2011 & 6393 & & 6892 & 241 \\
\hline 2012 & 4096 & & 4292 & 150 \\
\hline 2013 & 5612 & & 5738 & 201 \\
\hline 2014 & 7836 & & 7891 & 276 \\
\hline 2015 & 8155 & & 8212 & 287 \\
\hline 2016 & 7826 & & 7826 & 274 \\
\hline
\end{tabular}

Note: The monetary equivalents for each year are obtained by multiplying the percentage canal premium for each year by the mean price in the sample of properties $0-1500 \mathrm{~m}$ from a canal in each year. The table shows the amounts in nominal terms, converted to 2016 prices using the Consumer Price Index, and the annual equivalents assuming a discount rate of $3.5 \%$. 
${ }^{\text {i }}$ We use the term "canals" to refer to waterways that were dug out where there was no previous waterway, and rivers that were canalised to make them navigable.

ii The values that can be elicited through house prices are therefore what environmental economists refer to as use value, as opposed to, say, the satisfaction one might get from just knowing that such a resource exists without ever intending to visit or use it.

${ }^{i i i}$ For more information, one can refer to http://www.droitwichcanals.co.uk, https://www.waterways.org.uk/waterways/history/historiccampaigns/droitwichcanals/droitwichcanals and https://en.wikipedia.org/wiki/DroitwichCanal

iv This data linking was done for another project by colleagues at LSE.

${ }^{\mathrm{v}}$ For more details, refer to https://data.gov.uk/dataset/660ab8be-2912-4ef5-a8a9-7ed3111e34d1/canal-centre-line

${ }^{\text {vi }}$ The coefficients on our control variables indicate that there is also a premium of a similar magnitude for living near other natural rivers that extends over a wider range of distance, but again these are not statistically significant, and not the primary focus of this analysis.

vii These urban land cover figures come from NEA (2011).

viii This value is relative to other places, so is not necessarily an addition to the total value of the land or housing stock in England and Wales. 


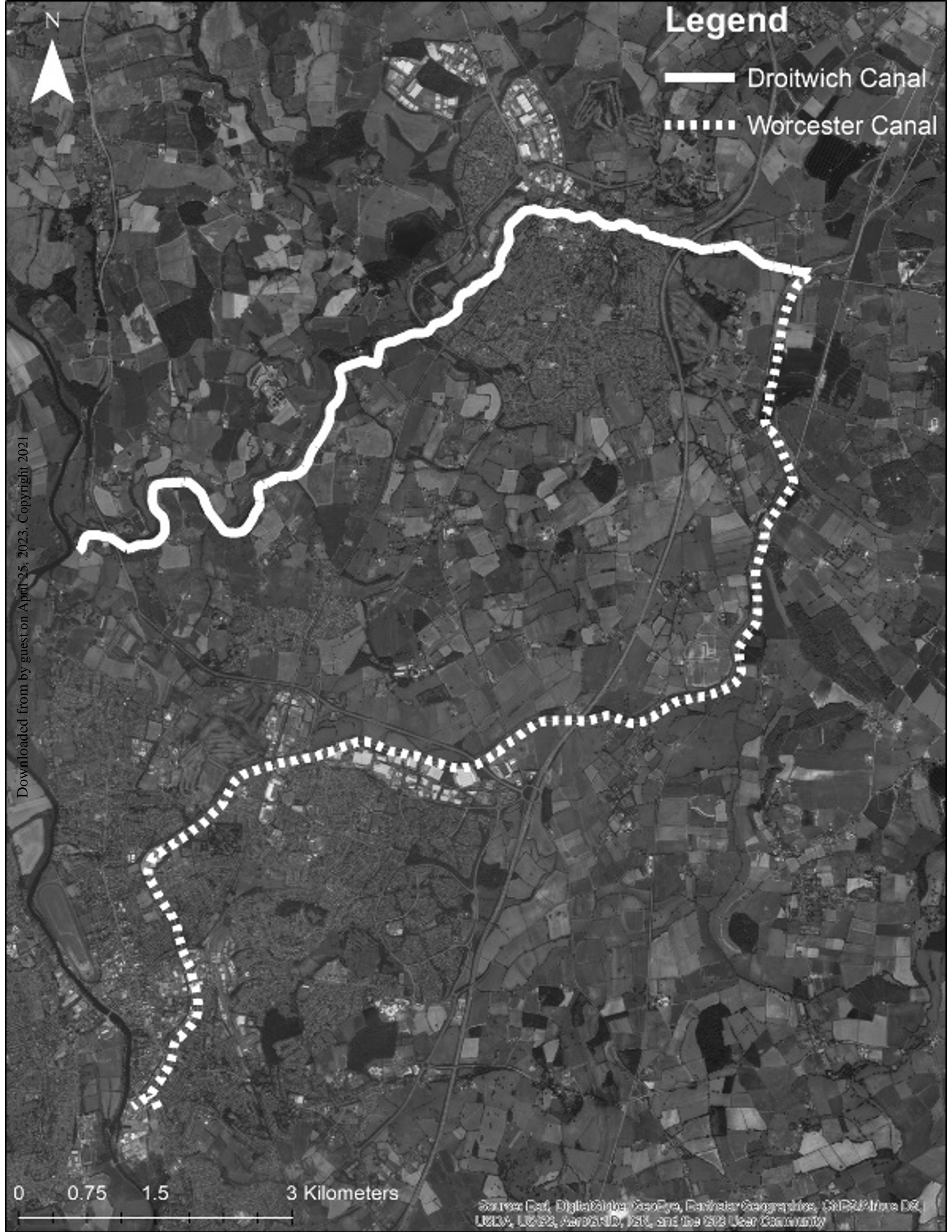




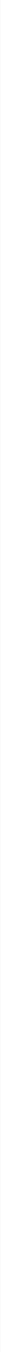




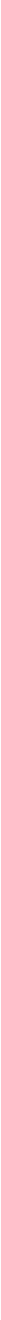




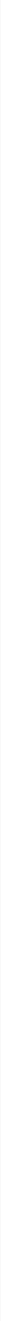




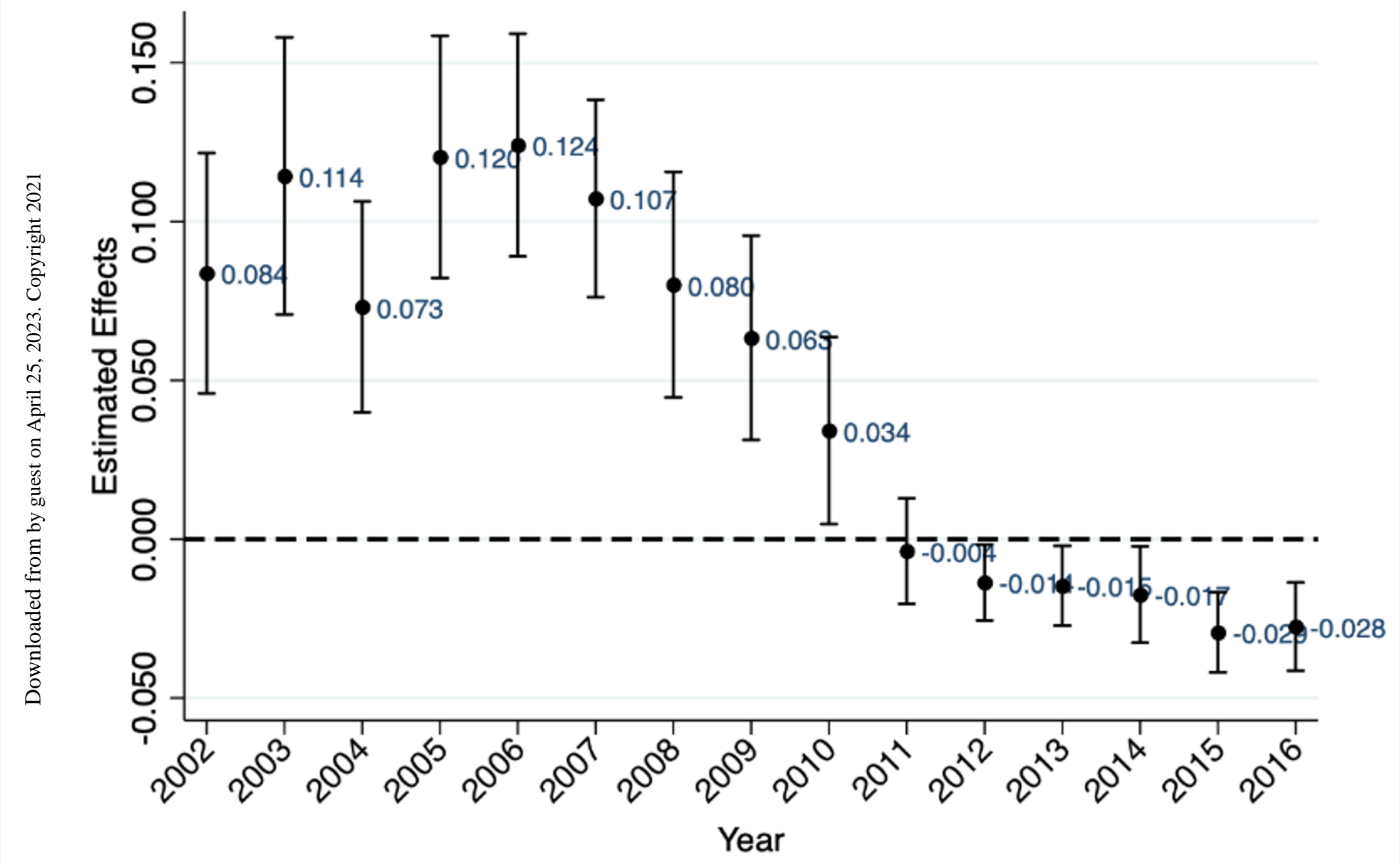




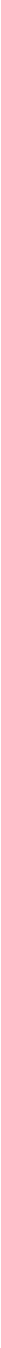



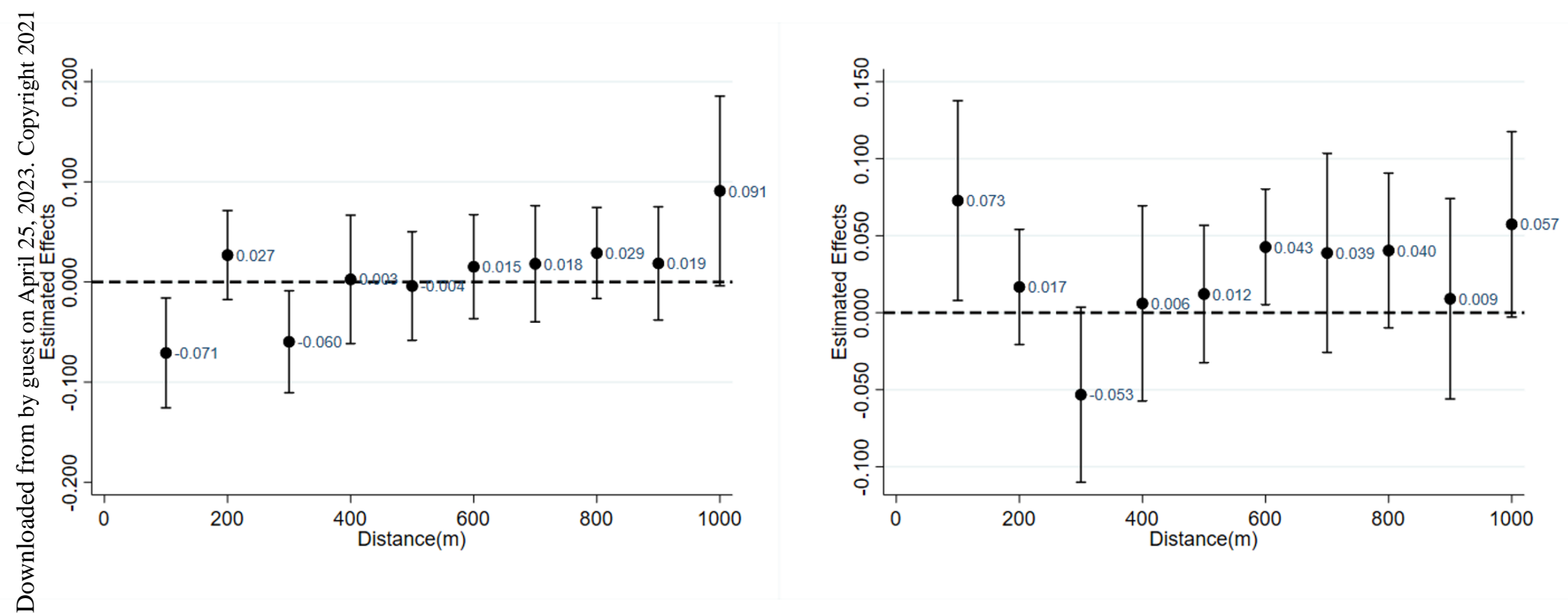